\title{
A Review of the Genus Alulatettix Liang (Orthoptera: Tetrigoidea: Tetrigidae)
}

\author{
XD LI ${ }^{1}$, WA DENG ${ }^{1}, \mathrm{ZM}$ ZHENG ${ }^{2}$ \\ 1Dept of Chemistry and Life Science, Hechi Univ, Yizhou Guangxi, China \\ ${ }^{2}$ Institute of Zoology, Shaanxi Normal Univ, Xi'an, China
}

\section{Keywords}

Alulatettix, new species, taxonomy

\section{Correspondence}

WA Deng, Dept of Chemistry and Life

Science, Hechi Univ, Yizhou 546300

Guangxi, China; dengweian5899@163.com

Edited by Roberto A Zucchi - ESALQ/USP

Received 2 February 2013 and accepted 25

March 2013

Published online 14 May 2013

(C) Sociedade Entomológica do Brasil 2013

\begin{abstract}
The taxonomy of the tetrigid genus Alulatettix Liang is reviewed. A new species, Alulatettix orthomarginalis $\mathrm{n}$. sp. is described. The annotated list and key to all known species of Alulatettix are given.
\end{abstract}

\section{Introduction}

The genus Alulatettix (Orthoptera: Tetrigidae) was erected by Liang (1993) with the type species Alulatettix yunnanensis Liang from China. Since Liang (1993), several new species of the genus Alulatettix have been described (Niu 1994, Zheng \& Zhou 1996, Wang \& Zheng 1997, Fu et al 1998, Zheng \& Zhong 2001, Zheng 2006, 2012, Zhong \& Zheng 2003, Tsai \& Yang 2005, Liang \& Jiang 2005, Deng et al 2006, 2009). Additionally, Tetrix fornicatus Ichikawa was transferred to Alulatettix by Zheng \& Zhong (2001). Deng et al (2006) revised the genus Alulatettix from China, and included 11 species. To date, the genus includes 17 known species distributed in China and Japan (Ichikawa 1993, Liang \& Zheng 1998, Zheng 2005, Tsai \& Yang 2005, Deng et al 2007).

In this paper, the genus of Alulatettix Liang is systematically revised and we include the clarification of the taxonomic status of the genus Alulatettix and determine the characters for species diagnosis. Information on biology and geographical distribution are also added, we describe Alulatettix orthomarginalis n. sp. and provide an updated key to the species.

\section{Material and Methods}

All specimens used in this study are deposited in the Institute of Zoology, Shaanxi Normal University, Xi'an, China, Department of Chemistry and Life Science, Hechi University, Yizhou, Guangxi, China, and the Research Institute of Entomology, Zhongshan University, Guangzhou, China.

Specimens were examined and illustrated by using a stereomicroscope (Guangzhou LISS Optical Instrument Ltd. XTL-1, China) at $\times 20$ magnification. Photographs were taken with a digital stereomicroscope (Sunny/DMSZM45) with a series of images montage using the program CombineZ5.3 (Hadley 2006). Morphological terminology and measurement landmarks followed those of Vickery \& Kevan (1983). Measurements are given in millimeters.

\section{Taxonomy}

\section{Alulatettix Liang}

Alulatettix Liang (1993, p. 73), Jiang \& Zheng (1998, p. 342), Liang \& Zheng (1998, p. 276), Zheng (2005, p. 342), Deng et al (2007, p. 306). Type species: A. yunnanensis Liang, 1993, China (Yunnan), by original designation. 
Description. Body size small, with small granules. Vertex protruding beyond anterior margin of eyes, with median carina. Vertex about 1.5-2.0 times as wide as an eye. Frons oblique, frontal costa slightly concave between lateral ocelli and protruding between the base of antennae in profile, longitudinal groove on frontal costa as wide as 1st antennal segment. Lateral ocelli situated middle of anterior margin of eyes. Eyes spherical. Pronotum distinctly tectiform, median carina, lateral carinae, and humeral angles of pronotum well defined; apex of hind process rounded or with triangular concavity; posterior margins of lateral lobes of pronotum with two concavities. Elytra and wings brachypterous. Fore and mid femora with nearly straight or wave-like ventral margin. First segment of hind tarsi longer than the third.

\section{Key to the species of Alulatettix Liang}

1. Anterior margin of pronotum straight... .2 - Anterior margin of pronotum protruding acute angular or obtuse angular.

2. Disk of pronotum with a pair of abbreviated carinae between shoulders

- Disk of pronotum without abbreviated carinae between shoulders

3. With numerous large and fine tubercles on dorsum of pronotum, median carina of pronotum interrupted; in profile, upper margin of pronotum wave-like Alulatettix interrupta Deng et al - Dorsum of pronotum smooth, median carina of pronotum complete, in profile, upper margin of pronotum arched. . Alulatettix angustivertex Tsai \& Yang 4. In profile, anterior part of upper margin of pronotum arched, middle part concave, posterior part arched; lower margins of fore and middle femora distinctly wave-like ...................... Alulatettix wudangshanensis Wang \& Zheng

- In profile, anterior half of upper margin of pronotum arched, posterior half flat

5. Width of vertex about two times that of one eye; hind wing reaching posterior margin of first segment of abdomen................ Alulatettix bamianshanensis Fu \& Zheng

- Width of vertex about 1.3-1.6 times that of one eye; hind wing reaching the posterior margin of second or third segment of abdomen .... 6 6. Width of vertex about 1.3 times that of one eye; hind wing reaching middle of second segment of abdomen; lower margins of middle femora straight; posterior margin of subgenital plate straight. Alulatettix rectimargina Zheng

- Width of vertex about 1.5-1.6 times that of one eye; hind wing reaching posterior margin of third segment of abdomen; lower margins of middle femora undulated
7. In profile, frontal costa concave between lateral ocelli; width of longitudinal furrow equal to that of first segment of antennae; prozona with lateral keels parallel; first segment of hind tarsi about 1.5 times longer than the third segment A. qinlingensis Deng et al - In profile, frontal costa straight between lateral ocelli; width of longitudinal furrow wider than that of first segment of antennae; prozona with lateral keels constricted backwards; first segment of hind tarsi about 2.0 times longer than third segment........ Alulatettix ochrotibis Deng \& Zheng 8. Anterior margin of pronotum acute-angularly protruding .. 9

- Anterior margin of pronotum obtuse angularly protruding .. 10

9. Width of vertex about 1.5 times that of one eye, anterior margin of vertex straight; middle femur 1.6 times width of tegmina; first segment of hind tarsi about 1.3 $\times$ longer than the third segments. A. guangxiensis Zheng \& Zhou

- Width of vertex about 2.0 times that of one eye, anterior margin of vertex curved; middle femur three times width of tegmina; first segment of hind tarsi about 2.0 times longer than the third segments. A. anhuiensis Zheng 10. Apex of hind pronotal process rounded ...................... 11 - Apex of hind pronotal process triangularely excised 14

11. Anterior margin of vertex rounded; in profile, upper margin of pronotum slightly arched... .. 12

- Anterior margin of vertex straight; in profile, upper margin of pronotum distinctly spherical 13 12. Disk of pronotum with a pair of abbreviated carinae between shoulders; ovipositor short, valves of ovipositor broad, upper valve 2.5 times as long as wide ............................ Alulatettix fornicata (Ichikawa)

- Disk of pronotum without abbreviated carinae between shoulders; ovipositor narrow and long, upper valvulae four times as long as width A. yunnanensis Liang 13. Apex of hind pronotal process reaching posterior end of abdomen; hind wings reaching posterior margin of third segment of abdomen Alulatettix bulbosus Zheng \& Zhong

- Apex of hind pronotal process reaching apex of supra-anal plate; hind wings reaching posterior margin of first segment of abdomen Alulatettix leyensis Liang \& Jiang

14. Ventral margins of mid femora straight. .. 15

- Ventral margins of mid femora undulated ....................... 16 15. In profile, upper margin of pronotum arcuate above fore leg, more straight in middle and posterior part; hind wings reaching posterior margin of second segment of abdomen; middle of posterior margin of subgenital plate of female triangularly projecting . Alulatettix zhengi Niu

- In profile, upper margin of pronotum arcuate; hind wings reaching the posterior margin of 1st segment of abdomen; posterior margin of subgenital plate of female with three teeth Alulatettix kunmingensis Zheng 
16. Width of longitudinal furrow of frontal ridge equal to width of first segment of antennae; lower margin of hind process of pronotum straight; mid-femur two times width visible part of tegmina A. orthomarginalis $\mathrm{n}$. $\mathrm{sp}$.

- Width of longitudinal furrow of frontal ridge wider than width of first segment of antennae; lower margin of hind process of pronotum curved; mid-femur three times width visible part of tegmina ... 17 17. In profile, frontal costa together with vertex forming an acute angle; posterior margin of subgenital plate of female straight Alulatettix wufengensis Zhong \& Zheng

- In profile, frontal costa together with vertex forming a right angle; in female, with a slender triangular projection in middle of posterior margin of subgenital plate Alulatettix chuxiongensis Zheng

Checklist of species of the genus Alulatettix

Alulatettix angustivertex Tsai \& Yang

Alulatettix angustivertex (Tsai \& Yang 2005, p. 53; holotype -male, China: Taiwan, Taitung; in the Department of Entomology, National Chung Hsing University, Taichung, Taiwan).

Specimens examined. No specimens were examined.

Data is recovered only from the literature.

Distribution. People's Republic of China: Taiwan.

Alulatettix anhuiensis Zheng

Alulatettix anhuiensis Zheng and Zhong 2001, p. 195 (holotype -female, China: Anhui, Guniujiang; in the Institute of Zoology, Shaanxi Normal University).

Specimens examined. One + , Anhui, Guniujiang, 15.viii.1984.

Distribution. People's Republic of China: Anhui.

Alulatettix bamianshanensis Fu \& Zheng

Alulatettix bamianshanensis (Fu et al 1998; p. 41; holotype -female, China: Hunan, Guidong; in the Institute of Zoology, Shaanxi Normal University).

Specimens examined. Six $\hat{\sigma}$, four $q$, Hunan, Linxiang, 4 Aug. 2010; one + , Hunan, Guidong, 10.viii.1996.

Distribution. People's Republic of China: Hunan.

Alulatettix bulbosus Zheng \& Zhong

Alulatettix bulbosus Zheng \& Zhong 2001, p. 197 (holotype -male, China: Hubei, Luotian; in the Institute of Zoology, Shaanxi Normal University).

Specimens examined. One $\partial^{\lambda}$, Hubei, Luotian, 14 Jue.1999; three $\hat{\delta}$, Hubei, Luotian, 10 Jue.1999; two $\delta$, four $q$, Zhejiang, Linan, 28.vi.2012.

Distribution. People's Republic of China: Hubei and Zhejiang.

Alulatettix chuxiongensis Zheng

Alulatettix chuxiongensis Zheng and Zhong 2001, p. 201 (holotype-female, China: Yunnan, Chuxiong; in the
Research Institute of Entomology, Zhongshan University; Zheng 2005, p. 345; Deng et al 2007, p. 310).

Specimens examined. Five $\hat{O}$, four $\mathcal{Q}$, Yunnan, Zhenxiong, 15 Aug. 2008; one + , Yunnan, Chuxiong, 21 July 1997; one 9 , Yunnan, Chuxiong, 1.viii.1975.

Distribution. People's Republic of China: Yunnan.

Alulatettix fornicata (Ichikawa)

Tetrix fornicatus (Ichikawa 1993, p. 2; holotype-female, Japan: Hatsutani Mts; in OMNH Osaka); A. fornicata (Ichikawa, 1993; Zheng and Zhong 2001, p.197).

Specimens examined. No specimens were examined.

Data is recovered only from the literature.

Distribution. Japan: Osaka prefecture, Mie prefecture, Kyoto prefecture, Hyogo prefecture, Okayama prefecture.

Alulatettix guangxiensis Zheng \& Zhou

Alulatettix guangxiensis Zheng \& Zhou 1996, p. 87 (holotype -male, China: Guangxi, xingan; in the Institute of Zoology, Shaanxi Normal University); Jiang and Zheng 1998, p. 34; Zheng 2005, p. 342; Deng et al 2007, p. 308.

Specimens examined. One $\hat{\partial}$, one + , Guangxi, xingan, 4.vi.1994.

Distribution. People's Republic of China: Guangxi.

Alulatettix interrupta Deng et al

Alulatettix interrupta (Deng et al 2006, p. 115; holotype -female, China: Guangxi, Beihai; in the Institute of Zoology, Shaanxi Normal University; Deng et al 2007, p. 307).

Specimens examined. One ${ }_{\text {+ }}$, Guangxi, Beihai, 8.viii . 2005. Distribution. People's Republic of China: Guangxi.

Alulatettix kunmingensis Zheng

Alulatettix kunmingensis (Zheng 2006, p. 365; holotype -female, China: Yunnan, Kunming; in the Institute of Zoology, Shaanxi Normal University; Deng et al 2007, p. 311).

Specimens examined. Two $\partial$, four + , Yunnan, Luliang, 7

Aug. 2006; two $\overbrace{}^{\lambda}$, two + , Yunnan, Kunming, 5.viii.2004. Distribution. People's Republic of China: Yunnan.

Alulatettix leyensis Liang \& Jiang

Alulatettix leyensis (Liang \& Jiang 2005, p. 56; holotype -female, China: Guangxi, Leye; in the Research Institute of Entomology, Zhongshan University).

Specimens examined. No specimens were examined.

Data is recovered only from the literature.

Distribution. People's Republic of China: Guangxi.

Alulatettix ochrotibis Deng \& Zheng

Alulatettix ochrotibis (Deng et al 2009, p. 259; holotype -male, China: Yunnan, Qiubei; in the Institute of Zoology, Shaanxi Normal University). 

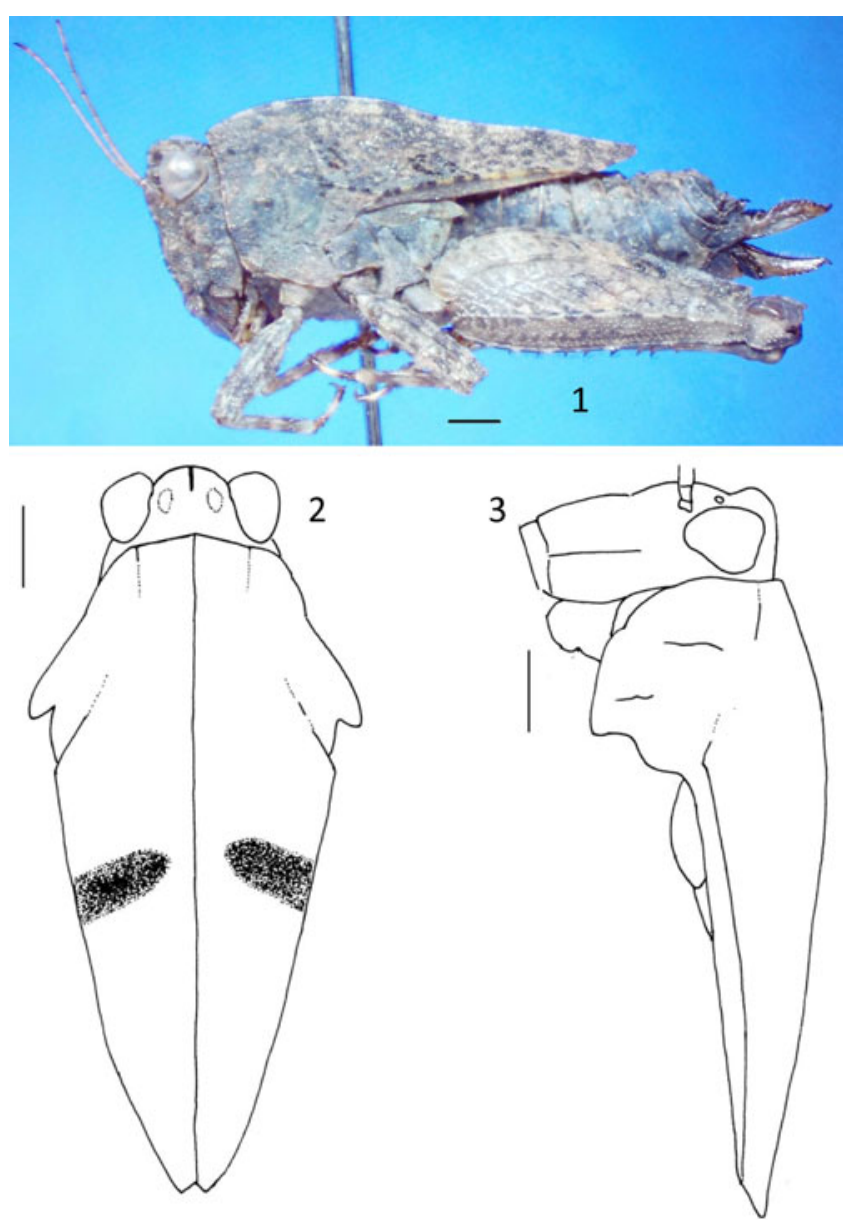

Figs 1-3 Alulatettix orthomarginalis $\mathrm{n}$. sp. female. 1 Lateral view of body; 2 head and pronotum, dorsal view; 3 head and pronotum, lateral view (scale bar $1 \mathrm{~mm}$ )

Specimens examined. Two $\widehat{\partial}$, four + , Yunnan, Qiubei, 5. viii. 2006.

Distribution. People's Republic of China: Yunnan.

\section{Alulatettix orthomarginalis n. sp. (Figs 1-3, 4-11, 12)}

\section{Description}

Female. (Fig 1) Size small. Head not projecting above upper level of pronotum (Fig 4). Anterior margin of vertex curved (Fig 2), slightly protruding beyond eyes, median carina conspicuous, the vertex between eyes 1.6 and 1.7 times wider than width of one eye from above. Vertex and frontal ridge curved in profile, frontal ridge concave between lateral ocelli (Fig 3), frontal ridge protruding archly between antennae, width of longitudinal furrow equal to width of first segment of antennae (Fig 5). Antennae filiform (Fig 6), 15 segmented, situated between lower margin of eyes (Figs 3-6), the eighth segment about five times as long as wide. Eyes globular. Lateral ocelli placed between middle of anterior margins of eyes (Figs 2 and 3). Pronotum in dorsal view tectiform, anterior margin obtuse angular (Fig 2), dorsal margin arched in profile (Figs 1 and 3). Posterior process of pronotum short, just reaching two thirds of hind femora, apex of process triangularly incised in middle (Fig 2). Lower margin of hind process straight (Figs 1 and 3), lateral carinae in metazona straight. Lateral carinae in prozona inconspicuous, parallel; humeral angle obtuse. Posterior margin of lateral lobes in lateral view with two concavities (Fig 3), the first extremely shallow; posterior angles of lateral lobes of pronotum turned downwards, with rounded apex. Tegmina smaller, brachypterous (Fig 8), elliptic, visible part of tegmen 3.5 times as long as wide. Hind wings strongly reduced as strips (Fig 8), just reaching the posterior margin of 1st segment of abdomen, in lateral view slightly exposed by the pronotum. Ventral margins of fore and mid femora slightly undulating (Fig 7); mid femur 2.0 times wider than visible part of tegmen. Hind femora stout, 3.0 times as long as wide; dorsal and ventral side of femora gentle dentate; pregenicular spine
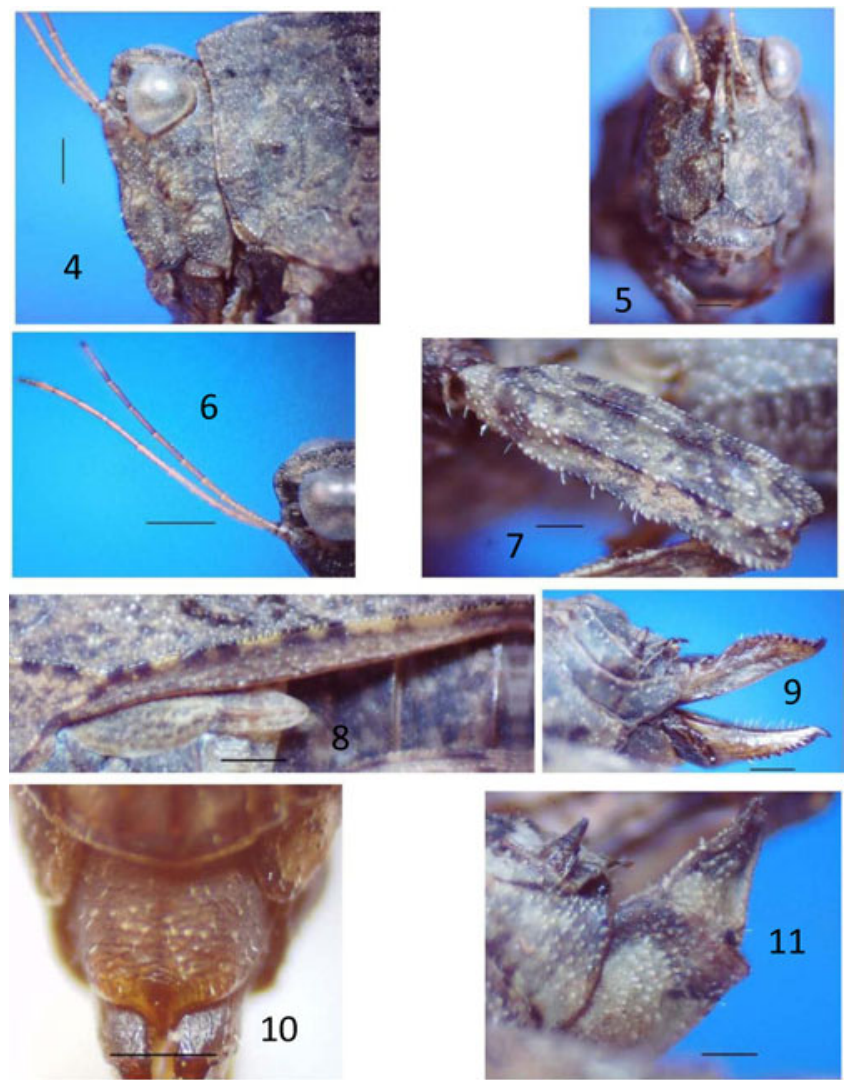

Figs 4-11 Alulatettix orthomarginalis n. sp. 4 Head, lateral view; 5 head, frontal view; 6 antennae; 7 middle femur, lateral view; 8 elytra and wings, lateral view; 9 ovipositor of female, lateral view; 10 subgenital plate of female, ventral view; 11 subgenital plate of male, lateral view (scale bar $1 \mathrm{~mm}$ ) 


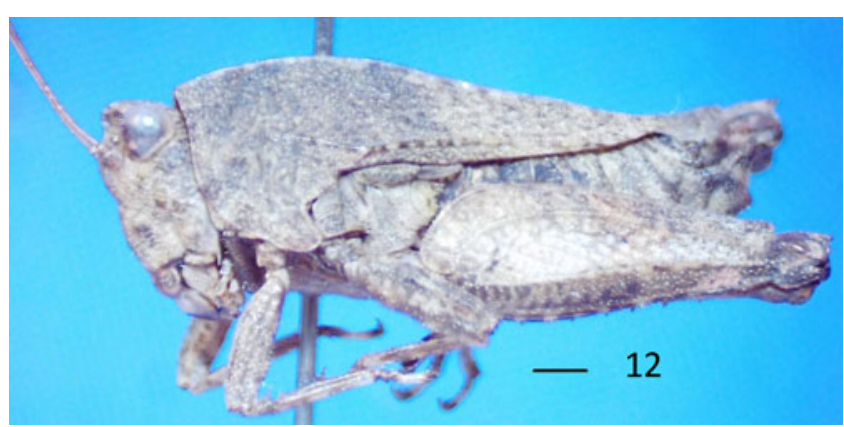

Fig 12 Alulatettix orthomarginalis n. sp. male-lateral view of body (scale bar $1 \mathrm{~mm}$ )

rectangular; genicular spine acute. Outer side of hind tibia with seven or eight spines, inner side with eight or nine spines. First segment of hind tarsi 1.6 times longer than the third segment; third pulvillus of first tarsus longer than first or second, apices of the first and the second pulvilli sharp, apex of the third pulvillus rectangular. Ovipositor narrow and long: upper valve 3.0 times as long as wide, upper and lower valves with slender saw-like teeth (Fig 9). Length of subgenital plate slightly less than its width; posterior margin of subgenital plate triangularly projecting (Fig 10).

Body dark brown, with a pair of dark spots behind shoulders (Fig 2). Hind tibia dark brown.

Male. (Fig 12) Size in males slightly smaller than in females. Vertex between eyes 1.4 and 1.5 times wider than width of one eye from above, subgenital plate short, cone-shaped (Fig 11). Other structures and coloration same as female.

Measurements. Length of body: $\delta^{\uparrow} 9.0-9.5 \mathrm{~mm}, ~+11-11.5 \mathrm{~mm}$; length of pronotum: $0.0-6.5 \mathrm{~mm}, 97.5-8.0 \mathrm{~mm}$; length of hind femur: ${ }^{\widehat{T}} 5.5-6.0 \mathrm{~mm}$, + $6.0-6.6 \mathrm{~mm}$.

Type material. Holotype: female. China, Guizhou prov., Chishui (Wuzhufeng, Suoluo Nature Reserve), $28.5 \mathrm{~N}$, 105.7E, 1,000 m asl, 13.viii.2012, collected by Wei-An DENG. Paratypes. Four male and two female, same data as for holotype. Material is deposited in the Institute of Zoology, Shaanxi Normal University, Xi'an, China.

\section{Diagnosis}

Alulatettix orthomarginalis is similar to $A$. wufengensis and $A$. chuxiongensis from which it differs in the vertex and frontal ridge curved in profile, the width of longitudinal furrow of frontal ridge equal to width of the first segment of antennae, the lower margin of hind process straight, the midfemur 2.0 times wider than the visible part of tegmen, and in the triangularly projecting posterior margin of female subgenital plate.
Etymology. The species name is derived from the Latin ortho and marginis, meaning lower margin of hind process straight.

Distribution. People's Republic of China, Guizhou.

Alulatettix qinlingensis Deng et al

Alulatettix qinlingensis Deng et al 2006, p. 114 (holotype -male, China: Shaanxi, Xian; in the Institute of Zoology, Shaanxi Normal University).

Specimens examined. Four $\hat{\sigma}$, four + , Shaanxi, Xian, 4.vi. 2005.

Distribution. People's Republic of China: Shaanxi.

Alulatettix rectimargina Zheng

Alulatettix rectimargina (Zheng 2012, p. 8; holotypefemale, China: Yunnan, Ruili; in the Institute of Zoology, Shaanxi Normal University).

Specimens examined. One + , Yunnan, Ruili, 7.viii.2005. Distribution. People's Republic of China: Yunnan.

Alulatettix wudangshanensis Wang \& Zheng

Alulatettix wudangshanensis (Wang \& Zheng 1997, p. 57; holotype-male, China: Hubei, Danjiangkou; in the Institute of Zoology, Shaanxi Normal University; Liang \& Zheng 1998, p. 177).

Specimens examined. Nine $\widehat{\partial}$ eight $q$, Hubei, Danjiangkou, 13 July 1990; One + , Hubei, Shennongjia, 21.vii.1990.

Distribution. People's Republic of China: Hubei.

Alulatettix wufengensis Zhong \& Zheng Alulatettix wufengensis Zhong \& Zheng 2003, p. 167 (holotype-female, China: Hubei, Wufeng; in the Research Institute of Entomology, Zhongshan University). Specimens examined. One 9 , Hubei, Wufeng, 15.viii.2000. Distribution. People's Republic of China: Hubei.

\section{Alulatettix yunnanensis Liang}

Alulatettix yunnanensis (Liang 1993; p. 73; holotype-male, China: Yunnan, Kunming; in the Research Institute of Entomology, Zhongshan University; Liang and Zheng 1998, p. 178; Zheng 2005, p. 344; Deng et al 2007, p. 309).

Specimens examined. Two $\hat{O}$, three $q$, Yunnan, Kunming, 4 Aug. 2005; one $\partial$, three $q$, Yunnan, Dali, 6.vii.1995.

Distribution. People's Republic of China: Yunnan.

\section{Alulatettix zhengi Niu}

Alulatettix zhengi (Niu 1994; p. 35; holotype-male, China: Henan, Xixia; in the Institute of Zoology, Shaanxi Normal University; Liang and Zheng 1998, p. 179).

Specimens examined. One $\widehat{\partial}$, Henan, Xixia, 6 Jue. 1987; one + , Henan, Lushan, 28.iii.1992; one + , Henan, Xixia, 30.vi.1986 Distribution. People's Republic of China: Henan. 


\section{Discussion}

The original description of the genus was exclusively based on characters from external morphology. The morphology of Alulatettix is quite homogeneous and species can be differentiated mostly by the brachypterous elytra and wings. Recent molecular studies based on $A$. qinlingensis cytochrome oxidase I (Fang et al 2010) demonstrated Alulatettix to be closely related to the genus Tetrix Latreille. Alulatettix and Tetrix belong to the subfamily Tetriginae, and both of these genera are similar in the head not projecting above upper level of pronotum and the posterior margin of lateral lobes in lateral view with two concavities, but they differ in the shape of pronotum and degree of development of tegmina and hind wings. Tetriginae are one of the most basal members of Tetrigoidea, but the phylogenetic studies focusing on the relationships within Tetriginae are limited. Therefore, phylogenetic relationships between Alulatettix and other Tetriginae genera are not well understood.

Species of the genus Alulatettix are usually associated with, but not limited to, shady environments, living under fallen leaves or grasses in tropical rainforests. Some (Mao et al 2011) have suggested that the brachypterous hind wings are not adapted for flying. The diet is consisted mainly of algae growing on moist ground, along with lichens and some forms of humus. Species of Alulatettix generally overwinter as adults. Almost all species of Alulatettix are distributed in the Oriental region, except one species known from the east part of the Palaearctic region (Japan: Honshu Island; Zheng 2012).

Acknowledgments The project was supported by the National Natural Science Foundation of China (31160433) and Guangxi Natural Science Foundation (no. 0991266) and Program for Excellent Talents in Guangxi Higher Education Institutions (08034).

\section{References}

Deng WA, Zheng ZM, Wei SZ (2006) A taxonomic study of the genus Alulatettix Liang (Orthoptera: Tetrigoidea: Tetrigidae) from China. Acta Entomol Sin 49(1):112-117 (in Chinese with English summary)

Deng WA, Zheng ZM, Wei SZ (2007) Fauna of the Tetrigoidea from Yunnan and Guangxi. Guangxi Science \& Technology Press, Nanning, $p 458$ (in Chinese with English summary)

Deng WA, Wang YF, Zheng ZM, Wei SZ (2009) A new species of the genus Alulatettix Liang (Orthoptera: Tetrigoidea: Tetrigidae) from Yunnan, China. Entomotaxonomia 31(4):259-262
Fang N, Xuan WJ, Zhang YY, Jiang GF (2010) Molecular phylogeny of Chinese Tetrigoids (Orthoptera, Tetrigoidea) based on the mitochondrial cytochrome coxidase I gene. Acta Zootaxonom Sin 35(4):696-702 (in Chinese with English summary)

Fu P, Zheng ZM, Huang JH (1998) A preliminary investigation of pygmy locusts in Bamianshan Natural Reserve of Hunan Province. J Hunan Agric Univ 24(2):129-133 (in Chinese with English summary)

Hadley, A (2006) CombineZ5. Available from: http://www.hadleyweb. pwp.blueyonder.co.uk/CZ5/combinez5.htm

Ichikawa A (1993) Four new species of the genus Tetrix (Orthoptera: Tetrigidae) from Japan. Akitu, New Series 135:1-8

Jiang GF, Zheng ZM (1998) Grasshoppers and locusts from Guangxi. Guangxi Normal University Press, 363 pp. (in Chinese with English summary)

Liang GQ (1993) A new genus and a new species of Tetrigidae (Orthoptera: Tetrigidae). Acta Zootaxonom Sin 18(1):73-75 (in Chinese with English summary)

Liang GQ, Jiang GF (2005) A new species of Alulatettix Liang from Guangxi, south China ( Orthoptera: Tetrigoidea ). In: Ren GD, Zhang RZ \& Shi FM. Classification and diversity of insects in China. China Agricultural Science and Technology Press, 56-57 (in Chinese with English summary)

Liang GQ, Zheng ZM (1998) Fauna Sinica, Insecta vol.12, (Orthoptera: Tetrigidae). Science Press, Beijing, 278 p (in Chinese with English summary)

Mao BY, Ren GD, Ou XH (2011) Fauna, distribution pattern and adaptability on Acridoidea from Yunnan. China Forestry Publishing House, 273-278 (in Chinese with English summary)

Niu Y (1994) A new species of genus Alulatettix from Henan (Orthoptera: Tetrigoidea). Entomol Res 1:35-36 (in Chinese with English summary)

Tsai MY, Yang JT (2005) A new species of the genus Alulatettix (Orthoptera: Tetrigidae) from Taiwan. J Orthoptera Res 14(1):53-56

Vickery VR, Kevan DK McE (1983) A monograph of the orthopteroid insects of Canada and adjacent regions. Memoir, 13, Vol. II. Lyman Entomological Museum and Research Laboratory, Quebec, 1190$1230 \mathrm{pp}$

Wang YW, Zheng ZM (1997) A new species of genus Alulatettix from Hubei (Orthoptera: Tetrigoidea). Acta Zootaxonom Sin 22(1):57-59 (in Chinese with English summary)

Zheng ZM (2005) Fauna of the Tetrigoidea from Western China. Science Press, Beijing, p 501 (in Chinese with English summary)

Zheng ZM (2006) Four new species of Tetrigidae (Orthoptera: Tetrigoidea) from Yunnan Province. Entomotaxonomia 28(3):161168 (in Chinese with English summary)

Zheng ZM (2012) Key to the species of Mazarredia, Cotysoides and Alulatettix (Orthoptera: Tetrigoidea) from China with descriptions of two new species. J Shangqiu Normal Univ 28(12):1-10 (in Chinese with English summary)

Zheng ZM, Zhong YL (2001) The genus Alulatettix Liang from China (Orthoptera: Tetrigoidea). Orient Insects 35:193-202

Zheng ZM, Zhou SY (1996) Two new species of Tetrigidae from Guangxi (Orthoptera: Tetrigoidea). J Guangxi Normal Univ 14(1):87-89 (in Chinese with English summary)

Zhong YL, Zheng ZM (2003) Two new species of Tetrigidae (Orthoptera: Tetrigoidea) from Hubei Province, China. Entomotaxonomia 25(3):169-171 (in Chinese with English summary) 